\title{
Revision Surgery for Vestibular Schwannomas
}

\author{
Kevin A. Peng ${ }^{1}$ Brian S. Chen ${ }^{3}$ Mark B. Lorenz ${ }^{2}$ Gregory P. Lekovic ${ }^{1}$ Marc S. Schwartz ${ }^{1}$ \\ William H. Slattery ${ }^{1}$ Eric P. Wilkinson ${ }^{1}$
}

${ }^{1}$ House Clinic, Los Angeles, California, United States

${ }^{2}$ Alaska Center for Ear, Nose and Throat, Anchorage, Alaska, United States

${ }^{3}$ Ear Nose and Throat Surgery Clinic, William Beaumont Army Medical Center, El Paso, Texas, United States

Address for correspondence Kevin A. Peng, MD, Associate, House Clinic, 2100 W, 3rd Street, Suite 111, Los Angeles, CA 90057 , United States (e-mail: kpeng@houseclinic.com).

J Neurol Surg B 2018;79:528-532.

\section{Introduction}

Vestibular schwannomas are benign neoplasms of the vestibular nerve occurring in the internal auditory canal (IAC) and cerebellopontine angle. Their incidence has been estimated at 2 per 100,000 individuals. ${ }^{1}$ Options for the management of vestibular schwannomas include observation, stereotactic radiation, and microsurgical resection. While the average growth rate for vestibular schwannomas is approximately $1.2 \mathrm{~mm}$ per year, ${ }^{2}$ individual patient characteristics, including tumor growth pattern, degree of hearing loss and vertigo, and patient age, guide optimal management. ${ }^{3}$

The three most common surgical approaches for the resection of vestibular schwannomas are the translabyrinthine, received

October 5, 2017

accepted after revision

February 21, 2018

published online

April 9, 2018 (c) 2018 Georg Thieme Verlag KG Stuttgart · New York
DOI https://doi.org/ 10.1055/s-0038-1635256. ISSN 2193-6331. 
middle fossa, and retrosigmoid approaches. While hearing cannot be preserved through the translabyrinthine approach, the direct access to the IAC and potential benefits in the preservation of facial nerve continuity makes it a favorable proposition for tumors exceeding $3 \mathrm{~cm}$ and for smaller tumors with significantly impaired hearing. ${ }^{4}$ In addition, the translabyrinthine approach largely avoids cerebellar retraction. The middle fossa and retrosigmoid approaches, on the other hand, carry advantages: the former allows excellent exposure of the IAC for the resection of intracanalicular tumors or tumors with limited cerebellopontine angle (CPA) involvement, ${ }^{5,6}$ whereas the latter can provide a clear view of the facial nerve at the root entry zone as well as the fundus and may be more suited for tumors with a larger CPA component. ${ }^{7}$ Ultimately, the decision for surgical approach lies with surgeon preference.

Complications of surgery for vestibular schwannomas include facial nerve paresis or paralysis, hearing loss, cerebrospinal fluid (CSF) leak, and tumor recurrence. ${ }^{8}$ Management of recurrent tumors following microsurgical resection depends on symptomatology and documented growth rate, but strong consideration is given to stereotactic radiation and revision surgery. ${ }^{9}$ Not surprisingly, revision surgery has been associated with increased complication rates. In this study, we seek to describe our institution's experience with revision surgery for vestibular schwannomas, with particular emphasis placed on the choice of surgical approach and perioperative complications.

\section{Materials and Methods}

\section{Patients}

This study received Institutional Review Board approval at St. Vincent Medical Center, Los Angeles, California, United States. An internal database of patients undergoing surgery for vestibular schwannomas between January 1985 and June 2015 was reviewed. Inclusion criteria were as follows: surgery performed on the same anatomical side following a history of prior surgery for vestibular schwannoma with an original pathological diagnosis of vestibular schwannoma, at our institution or at any other institution, with or without a diagnosis of neurofibromatosis type 2 (NF2), with or without a history of radiation therapy. Indication for surgery was a growing residual tumor in all cases. Patients with NF2 who underwent one surgery on each side did not meet inclusion criteria for revision surgery and were specifically excluded. Demographic and clinical data were aggregated.

Tumor dimensions were obtained from cross-sectional imaging, and the largest dimension from measurements in three planes-craniocaudal, anteroposterior, and transverse, including any IAC component-was taken as the tumor size.

Factors behind the choice of surgical approach for the revision surgery varied. Patients who had previously undergone a translabyrinthine approach usually underwent a second translabyrinthine approach for the revision surgery. Similarly, patients with no serviceable hearing following the first surgery often underwent a translabyrinthine approach for the revision surgery. However, no strict criteria were used when choosing the specific surgical approach, and the decision for approach was made on a case-by-case basis.

The decision for the extent of resection was generally taken intraoperatively; severe adherence to the brainstem or the facial nerve or lack of a clean plane of dissection led to the intraoperative decision for a partial resection. However, if the tumor was documented at the time of previous surgery to be adherent to the brainstem or the facial nerve, a partial resection was planned preoperatively.

\section{Statistical Analysis}

Mann-Whitney U and Kruskal-Wallis tests were employed to compare facial nerve outcomes with patients stratified by various characteristics. The Dunn-Bonferroni test was used as posthoc testing following any significant differences noted with the Kruskal-Wallis test. Statistical analysis was performed with SPSS (IBM, Armonk, New York, United States).

\section{Results}

In total, 231 unique patients, 102 males and 129 females, who underwent 250 revision surgeries within the study period were identified, with a mean length to follow-up of 30 days (range: 4 days to 1.75 years). The mean age was 43 years (range: $12-88$ years; - Table $\mathbf{1}$ ).

The mean number of prior surgeries was 1.26 (range: $1-$ 4). Thirty-six surgeries followed a prior resection at our institution; 197 followed surgeries performed at other institutions. Twenty-two (10\%) patients had undergone stereotactic radiation or other radiotherapy before the present surgery. Of the 15 patients who underwent more than one revision surgery at our institution, 9 carried a diagnosis of NF2 whereas 6 did not.

Surgical approaches included the translabyrinthine approach ( $n=217,87 \%$ ), the transcochlear extension of the translabyrinthine approach $(n=14,6 \%)$, the middle fossa approach ( $n=13,5 \%$ ), and the retrosigmoid approach ( $n=6,2 \%)$. Gross total resection was achieved in 212 surgeries (85\%); preoperative planned partial resection was performed in 11 surgeries (4\%), whereas an intraoperative decision for partial resection was made in 22 surgeries (9\%).

Surgeries lasted an average of 4.6 hours (range: 112 hours). Mean tumor size at the time of surgery as $2.6 \mathrm{~cm}$ (range: $0.5-6.9 \mathrm{~cm}$ ). Mean surgical time was 4.6 hours (range: 1-12 hours). Estimated blood loss, on average, was $342 \mathrm{~mL}$ (range: $40-3,000 \mathrm{~mL}$ ). Intraoperative transfusion was performed during 30 surgeries (14\%), with a mean transfusion of 1.4 units.

Facial nerve function was analyzed separately for patients with and without a diagnosis of NF2. For non-NF2 patients, the mean preoperative facial nerve function, as graded on the House-Brackmann scale, ${ }^{10}$ was 2.7 (range: $1-6$ ). The mean immediate postoperative facial nerve function (defined as facial nerve function within the first 24 hours following surgery) was 3.2 (range: 1-6), and the mean facial nerve function at last follow-up was 3.8 (range: 1-6). For patients with NF2, the mean preoperative facial nerve function was 2.7 (range: 1-6). The mean immediate postoperative facial 
Table 1 Patient characteristics

\begin{tabular}{|c|c|c|}
\hline & Number & Percentage \\
\hline \multirow[t]{2}{*}{ Gender } & 103 males & 44 \\
\hline & 131 females & 56 \\
\hline \multirow[t]{2}{*}{ Laterality } & 125 right & 50 \\
\hline & 124 left & 50 \\
\hline \multirow{2}{*}{$\begin{array}{l}\text { Location of prior } \\
\text { surgery }\end{array}$} & Own institution: 36 & 14 \\
\hline & $\begin{array}{l}\text { Other institution: } \\
197\end{array}$ & 86 \\
\hline $\begin{array}{l}\text { Preoperative } \\
\text { irradiation }\end{array}$ & 22 & 10 \\
\hline $\begin{array}{l}\text { Neurofibromatosis } \\
\text { type } 2\end{array}$ & 86 & 37 \\
\hline \multirow[t]{4}{*}{ Surgical approach } & $\begin{array}{l}\text { Translabyrinthine: } \\
217\end{array}$ & 87 \\
\hline & Transcochlear: 14 & 6 \\
\hline & Middle fossa: 13 & 5 \\
\hline & Retrosigmoid: 6 & 2 \\
\hline \multirow[t]{3}{*}{ Extent of resection } & Gross total: 212 & 85 \\
\hline & Subtotal: 33 & 13 \\
\hline & $\begin{array}{l}\text { Decompression } \\
\text { only: } 4\end{array}$ & 2 \\
\hline $\begin{array}{l}\text { Intraoperative } \\
\text { transfusion }\end{array}$ & 30 & 14 \\
\hline $\begin{array}{l}\text { Cerebrospinal fluid } \\
\text { leak }\end{array}$ & 21 & 8.4 \\
\hline \multirow{2}{*}{$\begin{array}{l}\text { Ventriculoperitoneal } \\
\text { shunt }\end{array}$} & 2 & 0.8 \\
\hline & Mean & Range \\
\hline Age (years) & 42.9 & $12-88$ \\
\hline Length to follow-up & $30 \mathrm{~d}$ & $4 \mathrm{~d}$ to $1.8 \mathrm{y}$ \\
\hline $\begin{array}{l}\text { Number of prior } \\
\text { surgeries }\end{array}$ & 1.26 & $1-4$ \\
\hline $\begin{array}{l}\text { Size of tumor at } \\
\text { surgery }(\mathrm{cm})\end{array}$ & 2.6 & $0.5-6.9$ \\
\hline $\begin{array}{l}\text { Operating time } \\
\text { (hours) }\end{array}$ & 4.6 & $1-12$ \\
\hline $\begin{array}{l}\text { Estimated blood } \\
\text { loss }(\mathrm{mL})\end{array}$ & 342 & $40-3,000$ \\
\hline
\end{tabular}

Note: Reported percentages are calculated using number of patients for whom data were available.

nerve function was 3.8 (range: 1-6), and the mean facial nerve function at last follow-up was 3.9 (range: 1-6; - Fig. 1 and -Table 2). When comparing facial nerve function between non-NF2 and NF2 groups, there was no significant difference when comparing preoperative values $(p=0.694$; Mann-Whitney U), immediate postoperative values $(p=0.094$; Mann-Whitney $\mathrm{U})$, and values at last follow-up $(p=0.625$; Mann-Whitney U).

Facial nerve function was further analyzed separately for patients who had a history of radiation therapy preceding
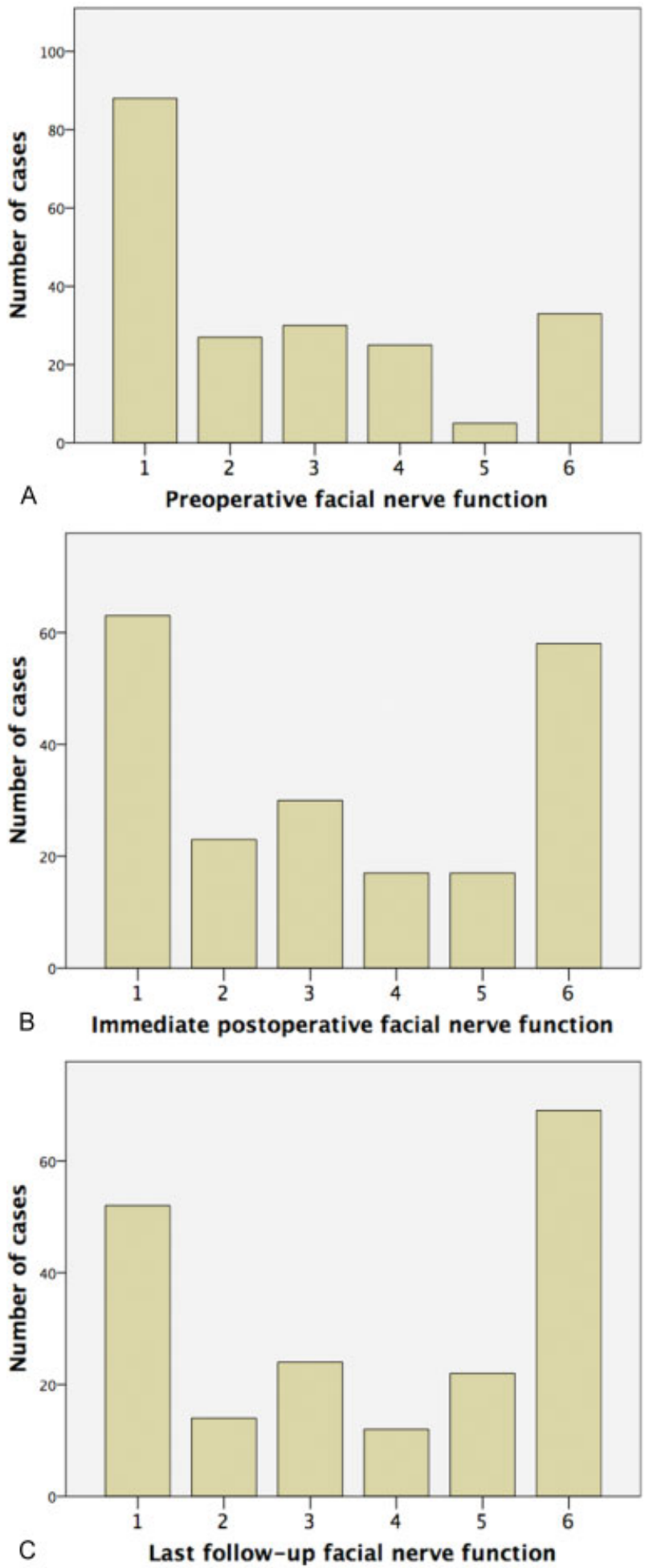

Fig. 1 Distribution of facial nerve function (A) preoperatively, (B) immediate postoperatively, and (C) at last follow-up (mean duration, 30 days), as graded on the House-Brackmann scale.

the revision surgery and those who did not. There was no significant difference between radiation and nonradiation groups with respect to preoperative facial nerve function (Mann-Whitney $\mathrm{U} ; \boldsymbol{p}=0.075$ ) as well as postoperative facial nerve function $(p=0.148)$. 
Table 2 Facial nerve function for all patients preoperatively, immediate postoperatively, and at last follow-up (mean duration, 30 days), as graded on the House-Brackmann scale

\begin{tabular}{|l|l|l|l|}
\hline & $\begin{array}{l}\text { Preoperative } \\
(\%)\end{array}$ & $\begin{array}{l}\text { Immediate } \\
\text { postoperative } \\
(\%)\end{array}$ & $\begin{array}{l}\text { Last follow-up } \\
(\%)\end{array}$ \\
\hline I & $108(43 \%)$ & $63(30 \%)$ & $52(27 \%)$ \\
\hline II & $29(12 \%)$ & $23(11 \%)$ & $14(7 \%)$ \\
\hline III & $36(15 \%)$ & $30(14 \%)$ & $24(12 \%)$ \\
\hline IV & $25(10 \%)$ & $17(8 \%)$ & $12(6 \%)$ \\
\hline V & $9(4 \%)$ & $17(8 \%)$ & $22(11 \%)$ \\
\hline VI & $40(16 \%)$ & $60(29 \%)$ & $69(36 \%)$ \\
\hline
\end{tabular}

Preoperative facial nerve function did not depend on the extent of resection ( $p=0.195$; Kruskal-Wallis), but postoperative facial nerve function was significantly different among the extent of resection ( $p=0.016$ ). However, posthoc testing (Dunn-Bonferroni) revealed no significant pairwise differences between groups when comparing the extent of resection ( $p>0.05$ for all).

Preoperative facial function was significantly different among different surgical approaches ( $p=0.000$; KruskalWallis). Pairwise comparisons revealed that patients undergoing the transcochlear approach had worse preoperative facial nerve function than patients undergoing the middle fossa, retrosigmoid, and translabyrinthine approaches ( $p=0.000$ for all; Dunn-Bonferroni). Postoperative facial function was also significantly different among different surgical approaches ( $p=0.000$, Kruskal-Wallis). Pairwise comparisons revealed that patients undergoing the transcochlear approach had worse postoperative facial nerve function than patients undergoing middle fossa and retrosigmoid approaches ( $p=0.000$ and $p=0.015$, respectively, DunnBonferroni), but there was no significant difference between translabyrinthine and transcochlear approaches $(p=0.224$; Dunn-Bonferroni).

Twenty-one CSF leaks were encountered (8\%); of these, six cases required reoperation. Two (1\%) patients required eventual placement of a ventriculoperitoneal shunt. No perioperative mortality was noted.

Pathological analysis of the resection specimen confirmed a diagnosis of vestibular schwannoma in 233 cases (93\%); six specimens from revision surgeries were reported as meningiomas (2.4\%), whereas pathology was unavailable in 11 cases.

\section{Discussion}

While gross total resection is often performed in primary microsurgery for vestibular schwannomas, near-total and subtotal resections may be electively performed if involvement of adjacent structures, such as the facial nerve, is present. While the choice of surgical approach may be correlated with the extent of tumor removal, ${ }^{11,12}$ the extent of resection has been shown to be unrelated to tumor recurrence, which has been estimated at approximately $9 \%$ following primary microsurgery. ${ }^{12}$ Revision surgery is generally indicated in patients with growing residual or recurrent disease, and planar measurements have been shown to be adequate in trending growth of residual or recurrent tumors. $^{13}$

Previous series on revision surgeries for vestibular schwannomas emphasize the relatively higher rate of complications, including CSF leaks, new cranial nerve deficits, cerebrovascular accidents, and hematomas. ${ }^{14}$ Patients with residual or recurrent disease after a prior retrosigmoid approach may be successfully treated with a translabyrinthine or transcochlear approach. ${ }^{11}$

In this descriptive series, a majority of patients (87\%) underwent revision surgery through the translabyrinthine approach; a transcochlear approach was employed in an additional $6 \%$ of patients. In our experience, the translabyrinthine approach allows for excellent exposure and minimizes cerebellar retraction, and the transcochlear approach, often performed in a canal-wall-down fashion with blind sac closure of the external auditory canal, can provide additional access, particularly to the anterior extent of the tumor.

Unsurprisingly, preoperative and postoperative facial nerve functions were generally poorer than those encountered with primary surgeries, including when compared with a series of translabyrinthine surgeries performed at our own institution. ${ }^{15}$ Non-NF2 and NF2 patients did not differ significantly with respect to preoperative facial function, immediate postoperative facial function, or facial function at last follow-up. However, the mean length to follow-up was 30 days, with significant variation, and long-term facial nerve outcomes in this population are difficult to infer.

In this series, the CSF leak rate was $8 \%$. This is comparable to, or even slightly exceeds, published CSF leak rates for all vestibular schwannoma surgeries, which have been reported to range from 0 to $17 \%,{ }^{16-20}$ with most series reporting leak rates of approximately 5 to $6 \% .^{15,21,22}$ In our practice, both nasal and incisional CSF leaks following translabyrinthine or transcochlear craniotomy are treated with revision craniotomy, replacement of fat graft packing, and blind sac closure of the external auditory canal. For CSF leaks following middle fossa or retrosigmoid approach, a lumbar drain is the first line of therapy, and ventriculoperitoneal shunts are reserved for patients demonstrating dependence on a lumbar drain to abate the CSF leak.

A significant limitation of this study was the relatively short duration of follow-up for several patients, many of whom were evaluated in person only immediately preceding and several weeks following surgery. Long-term follow-up, particularly of facial nerve function, was therefore not available for many patients, and postoperative facial nerve function, as noted here, may underestimate the rates of recovery of function. Furthermore, neurologic complications and hearing status were not comprehensively documented.

\section{Conclusion}

Revision surgery for vestibular schwannomas, where indicated, is feasible and safe, and complication rates, including 
CSF leak rates, approximate those encountered with primary surgery. Our preferred approach is the translabyrinthine craniotomy, which can be expanded to include the transcochlear approach for greater exposure.

\section{References}

1 Stangerup SE, Caye-Thomasen P, Tos M, Thomsen J. The natural history of vestibular schwannoma. Otol Neurotol 2006;27(04): 547-552

2 Yoshimoto Y. Systematic review of the natural history of vestibular schwannoma. J Neurosurg 2005;103(01):59-63

3 Rutherford SA, King AT. Vestibular schwannoma management: what is the 'best' option? Br J Neurosurg 2005;19(04): 309-316

4 Lanman TH, Brackmann DE, Hitselberger WE, Subin B. Report of 190 consecutive cases of large acoustic tumors (vestibular schwannoma) removed via the translabyrinthine approach. J Neurosurg 1999;90(04):617-623

5 Friedman RA, Kesser B, Brackmann DE, Fisher LM, Slattery WH, Hitselberger WE. Long-term hearing preservation after middle fossa removal of vestibular schwannoma. Otolaryngol Head Neck Surg 2003;129(06):660-665

6 Irving RM, Jackler RK, Pitts LH. Hearing preservation in patients undergoing vestibular schwannoma surgery: comparison of middle fossa and retrosigmoid approaches. J Neurosurg 1998;88(05): 840-845

7 Colletti V, Fiorino F. Middle fossa versus retrosigmoid-transmeatal approach in vestibular schwannoma surgery: a prospective study. Otol Neurotol 2003;24(06):927-934

8 Samii M, Matthies C. Management of 1000 vestibular schwannomas (acoustic neuromas): surgical management and results with an emphasis on complications and how to avoid them. Neurosurgery 1997;40(01):11-21, discussion 21-23

9 Pollock BE, Lunsford LD, Flickinger JC, Clyde BL, Kondziolka D. Vestibular schwannoma management. Part I. Failed microsurgery and the role of delayed stereotactic radiosurgery. J Neurosurg 1998;89(06):944-948

10 House JW, Brackmann DE. Facial nerve grading system. Otolaryngol Head Neck Surg 1985;93(02):146-147
11 Sanna M, Falcioni M, Taibah A, De Donato G, Russo A, Piccirillo E. Treatment of residual vestibular schwannoma. Otol Neurotol 2002;23(06):980-987

12 Sughrue ME, Kaur R, Rutkowski MJ, et al. Extent of resection and the long-term durability of vestibular schwannoma surgery. J Neurosurg 2011;114(05):1218-1223

13 Tang S, Griffin AS, Waksal JA, et al. Surveillance after resection of vestibular schwannoma: measurement techniques and predictors of growth. Otol Neurotol 2014;35(07):1271-1276

14 Freeman SR, Ramsden RT, Saeed SR, et al. Revision surgery for residual or recurrent vestibular schwannoma. Otol Neurotol 2007;28(08):1076-1082

15 Brackmann DE, Cullen RD, Fisher LM. Facial nerve function after translabyrinthine vestibular schwannoma surgery. Otolaryngol Head Neck Surg 2007;136(05):773-777

16 Mamikoglu B, Wiet RJ, Esquivel CR. Translabyrinthine approach for the management of large and giant vestibular schwannomas. Otol Neurotol 2002;23(02):224-227

17 Falcioni M, Mulder JJ, Taibah A, De Donato G, Sanna M. No cerebrospinal fluid leaks in translabyrinthine vestibular schwannoma removal: reappraisal of 200 consecutive patients. Am J Otol 1999;20(05):660-666

18 Zhang Z, Wang Z, Huang Q, Yang J, Wu H. Removal of large or giant sporadic vestibular schwannomas via translabyrinthine approach: a report of 115 cases. ORL J Otorhinolaryngol Relat Spec 2012;74(05):271-277

19 Merkus P, Taibah A, Sequino G, Sanna M. Less than 1\% cerebrospinal fluid leakage in 1,803 translabyrinthine vestibular schwannoma surgery cases. Otol Neurotol 2010;31(02):276-283

20 Copeland WR, Mallory GW, Neff BA, Driscoll CL, Link MJ. Are there modifiable risk factors to prevent a cerebrospinal fluid leak following vestibular schwannoma surgery? J Neurosurg 2015; 122(02):312-316

21 Fishman AJ, Marrinan MS, Golfinos JG, Cohen NL, Roland JT Jr Prevention and management of cerebrospinal fluid leak following vestibular schwannoma surgery. Laryngoscope 2004;114(03): 501-505

22 Springborg JB, Fugleholm K, Poulsgaard L, Cayé-Thomasen P, Thomsen J, Stangerup SE. Outcome after translabyrinthine surgery for vestibular schwannomas: report on 1244 patients. J Neurol Surg B Skull Base 2012;73(03):168-174 